\title{
The Experience in the Application of "Action-oriented Teaching Approach" to Pediatric Nursing Teaching
}

\author{
Zhiyong ZHANG \\ Langfang Health Vocational College \\ Langfang,056000, China
}

\author{
Fangqiu LIU \\ Langfang Health Vocational College \\ Langfang,056000, China
}

\begin{abstract}
Pediatric nursing is a very important clinical nursing subject in the nursing program of health vocational college. The "action-oriented teaching approach" has been introduced by the authors to pediatric nursing classroom and a good teaching effect has been obtained, thus laying a solid foundation for the future pediatric clinical nursing work of students. The application of "action-oriented teaching approach" to the pediatric nursing teaching has fully inspired the learning enthusiasm and initiative of students and cultivated the students' ability to analyze and solve problems. Also, it is advantageous to the formation of the students' creative ability, strain capacity, independent working ability, cooperative ability, and coordinative ability, and can help train all students to be the talented personnel with comprehensive ability.
\end{abstract}

Keywords: Action-oriented Teaching Approach; Pediatric Nursing; Application Experience

\section{Introduction}

"Action-oriented teaching approach" is a very effective teaching philosophy that is introduced by higher vocational colleges in practice. It is composed of a series of specific teaching methods, including brain storm, card display, simulation teaching, role playing, case teaching, project guide, text guide, etc. It requires students to not only use head and also makes heart and hands work with head together in learning. In the whole teaching process, students have always been in a main position, and the teaching quality will be ultimately reflected from the improvement of the students' comprehensive quality.

Pediatric nursing is a very important clinical nursing subject in higher vocational colleges, for the purpose of training the "practical" pediatric nursing personnel with solid theories and skilled operations. At present, the traditional teaching methods such as "explanation" are not conducive to the realization of the teaching objective. While introducing the "action-oriented teaching approach" to pediatric nursing classroom, the students' ability in autonomous learning and how to learn can be trained, and simultaneously the comprehensive vocational ability of students can be improved, so that the ability of students can be fully developed.

\section{The application of "role playing"}

"Role playing" is a teaching method that is centered at students and teaching interaction, in order to improve the enthusiasm of the students to participate in teaching.

\subsection{The advantages of "role playing"}

First, limited resources can be effectively used, and the needed material and financial resources are scarce. In the meantime, it makes up for the 
inadequate clinical practice of health vocational schools.

Second, it is conducive to the specification of clinical words and deeds. Performers need to memorize the scripts before the performance, while these scripts are normative for nurse's words and deeds. By memorizing and reproducing these words and deeds, students in both performing and watching are trained in normative words and deeds.

Third, it is useful for the formation of the students' strain capacity. The students' strain capacity is greatly improved because "role playing" is applied. Students are required to undertake a variety of different roles, face different objects, and constantly make new replies according to new situation.

Fourth, the students' initiative for participation can be fully aroused and the learning enthusiasm can also be improved. The students in role playing must devote themselves heart and soul, seriously recite and remember the scripts, and repeatedly practice their own words and deeds and skilled operation, so that what they have learned is tremendously understood and memorized. For the students as audiences, on-site simulation performance is more lively and interesting than the lectures of teacher, and then they can more easily deepen the cognition and understanding of what they have learned.

Fifth, simulation environment is of authenticity and close to clinical practice. Role playing promotes the teaching to be more realistic and the learning to be more effective in the simulated real environment.

Sixth, simulation environment can produce a sense of security, in which students can relax to play. Because site for role playing is classroom or laboratory, students will feel secured and don't have to worry about the disputes between nurses and patients in the clinical work. Moreover, the people on site are the students and teachers they know well, so they will be mentally more relaxed. The students in role playing, therefore, can display their learned knowledge and skills to the maximum and improve the level of their clinical care in the performance.

\subsection{Possible problems in role-play and the countermeasures}

First, teaching objective must be clear, and the contents in performance must be closely related to the knowledge, skills and attitudes in teaching objective or the situations possible to experience in the pediatric clinical nursing work. Thus, these contents must be easy to perform, but also easy to accept. At the same time, scripts for role playing must be short, forceful, and easy to understand; the performance time should not be too long and is commonly controlled within 10 minutes, so as not to cause the burnout of performers and the boredom of audiences and affect the teaching effect.

Second, some teachers worry about role-playing teaching to make the classroom into a disorganized mess, and some worry about students to be ill-prepared, so that they are unable to achieve the expected teaching effect. In order to avoid these problems, teachers must make a detailed and careful plan in advance and write a detailed role play script.

Third, audiences are other students, who will gain knowledge from the watching process of role playing and also put forward some problems actively. If audiences are not active to watch, they won't be able to get result of learning. Thus, teachers have to put forward specific requirements for the students as audiences and ask them to fill in questionnaire after watching, in order to evaluate whether an actual learning effect is exerted after the performance.

Fourth, some students may find it difficult to enter the roles and even have the mood to resist. Under the circumstances, teachers and other students must constantly encourage role play students, urge them to practice repeatedly, and proficiently grasp what they will perform in order to increase their confidence, overcome the initial resistance and actively get involved in role playing. 
Fifth, a one-sided pursuit of artistic performance is not allowable in the process of role playing, but the purpose of role play must be stressed, so as to better master related knowledge, skills and attitudes. According to the actual teaching needs, the roles of pros and cons can be designed, so as to enhance persuasion by contrastive performance and deepen the understanding and memories of the learned.

\section{The application of "case teaching"}

A good teaching effect has been achieved by introducing "case teaching" to pediatric nursing classroom. "Case teaching" can also widen students' view, promote students' active learning and cultivate their creative spirit, creative ability and comprehensive quality.

\subsection{The advantages of "case teaching"}

First, students' interest in learning is fully stimulated. In the process of case teaching, the students' interest in learning is excited to a higher level, which is favorable to learn and understand the theoretical knowledge, but also makes the classroom atmosphere active. Students are the masters of the classroom, who receive and explore knowledge actively instead of passively. Thus, they can grasp the related problems revealed in cases and raise solutions after serious thinking.

Second, teaching contents are easy to learn, vivid and concrete. The teaching contents in "case teaching" are specific and give students a feeling of being on the scene, and can be easy to learn and understand plus a visual, intuitive and vivid teaching form.

Third, the wisdom of the masses is drawn. In the classroom, teachers discuss and think with students together, but do not sing a "monologue". Meanwhile, students will focus on the discussion of problems, but are not too busy to take notes. A good teaching effect has been received because the collective wisdom and strength are mobilized and the train of thoughts is easy to open.
Fourth, both teaching and learning are benefited. On the one hand, teacher is the leader of the whole teaching, controls the teaching process, and guides students to think, discuss, research and make a summary. On the other hand, Teachers can not only find their weaknesses and also learn a lot of perceptual materials from students through mutual discussion in the teaching.

Fifth, the overall teaching level of teachers is improved. Teachers must collect and classify the proper cases first and get a deep understanding of the related knowledge in the cases. Then, teachers must seize a chance to coordinate students in the concrete teaching process. Finally, teachers must possess a powerful integrated ability to make conclusion and comments after case analysis and discussion are ended.

Sixth, the initiative of students to learn is aroused. In teaching, the students' brain excitement is constantly transferred, and their concentration can be timely adjusted, making it easy for students to keep the best mental state all the time.

Seventh, it is helpful for the formation of the students' creative ability. With the application of "case teaching", the students' field of vision is greatly expanded, thus providing a space for students to widely think. The ultimate purpose of case teaching is to dig out the students' creative potentials through thinking and discussing concrete cases, but not to convey the final truth. Thus, what it really values is the process of thinking.

Eighth, it is favorable for widening the students' field of vision and exercising their ability in language expression.

\subsection{Points necessary to focus on in the application of "case teaching"}

First, case teaching has to be based on theories. That is, it should be implemented on the basis of theoretical learning.

Second, the ultimate objective of "case teaching" is to improve the students' ability to 
analyze and solve problems through case analysis. Therefore, case analysis cannot only stay at the superficial level, and a thorough analysis is crucial definitely.

Third, teachers must control all details of discussion to guide the case discussed direction well.

Fourth, the process of "case teaching" consumes a lot of time and also has higher requirements for both teachers and students. For this reason, it is necessary to choose some high-quality cases fit for the teaching needs.

\section{Conclusions}

Through the comprehensive use of the above "role playing" and "case teaching" in the "action-oriented teaching approach", the teaching quality and effect of the pediatric nursing program in Langfang Health Vocational College have been significantly improved, and also the student's grade point average and excellence have been significantly superior to those in the traditional teaching methods. For these reasons, it is worthy of promotion and application.

\section{Acknowledgement}

This paper aided financially by the "twelfth five-year plan" key education science project of
Langfang, Hebei Province-Study on the Application of "Action-oriented Teaching Approach" to Pediatric Nursing Teaching (No.121056; host: LIU Fangqiu).

\section{References}

[1] Dandan WANG, Zhijian LIU. The Practical Application of Action-oriented Teaching Model to Course Basic Nursing Application Technology [J]. Heilongjiang Science and Technology Information, 2012 (19).

[2] Hui ZHOU. Teacher's Role Transformation under Action-oriented Teaching Idea [J]. Family Education in the World, 2013 (12).

[3] Xiaohui ZHU. Exploration on the Implementation of Action-oriented Teaching [J]. China's Electricity Education, 2010 (15).

[4] Mei FENG. Discussion on the Tasks Multiplicity of Foreign Language Teachers in the Action-oriented Teaching [J]. Value Engineering, 2011 (27).

[5] Dehui YANG, Binlong KAN, Lixin ZHANG. Analysis on Action-oriented Teaching [J]. Profession, 2011 (29). 